\title{
Women's Support for UKIP: Exploring Gender, Nativism, and the Populist Radical Right (PRR)
}

\section{Introduction}

In May of 2015, the UK Independence Party (UKIP), led by Nigel Farage, garnered 3,881,099 votes from the UK public in the national general elections. While this resulted in only 1 parliamentary seat, the vote share for UKIP was $12.6 \%$ making them the third most popular party amongst UK voters (behind the Conservatives who held $36.9 \%$ and Labour with $30.4 \%$ ). In the 2016 local elections, UKIP were able to increase their share of seats across Local Councils by 26, giving them a total of 58 seats across England. UKIP Wales also gained 7 regional seats in the Welsh Assembly, and 2 seats in the London Assembly. UKIP's 2014 manifesto makes clear their anti-EU stance, and at the same time focuses on the 'real alternative' they provide to other UK political parties that, they claim, fail to tell the truth about issues such as immigration, jobs and housing (UKIP, 2014). While UKIP's vote share was greatly diminished in the 2017 General Election, an exploration of UKIP as a populist radical right (PRR) party is still worthy of academic attention in the context of wider discussions about the nature of PRR parties in Europe (c.f. Mudde 2007; Akkerman 2015)

Populist radical right parties emerged in Europe in the 1990s and have become an important feature of western democracies (Akkerman 2015), achieving electoral success in the past decade in many European countries (Spierings and Zaslove 2015). PRR parties have also been successful to the extent that some populist ideas have been incorporated into mainstream political parties (Mudde 2004). While some have argued that populism exists as a political style (Moffitt and Tormey 2014) or a political strategy (Weyland 2001), Mudde (2004) and Speirings et al (2015) consider populism to be a 'thin centred-ideology'. PRR parties often self-define as antiestablishment and anti-ideological and suggest their policies and approaches are 'common-sense' (Mayer 2013). They claim to express the will of the people, and as such do not seek to change 'the people' (their way of life, value-systems, etc), but rather seek to emancipate them from the oppression they currently experience under the rule of the political elites (Mudde 2014). Mudde (2014) argues that populism in this sense is reactive, rather than original or generative, and PRR parties often emerge in times of upheaval or crisis and capitalize on feelings of discontent and sometimes fear in order to present themselves as viable alternatives to mainstream politics. There have been a number of recent European studies that suggest there has been an increase in people supporting and voting for PRR parties, with some researchers suggesting this surge is the result of a shift in voters' concerns about social and cultural changes, as opposed to concerns about the economy or fiscal issues (Webb and Bale 2014; Van der Brug and Van Spanje 2009; Mudde 2009).

This paper adds to existing literature on the nature of PRR parties by looking at the particular context of the UK, offering empirical evidence from supporters of England's leading PRR party: UKIP. Data drawn from in-depth qualitative interviews are presented here, collected as part of a wider study on women and nationalist movements in the UK (see Mulholland, this collection). This paper will explore issues related to women's support for UKIP as a PRR party, and will focus on a key characteristic associated with PRR support as outlined by Mudde (2007): nativism. Mudde (2007) provides an in-depth overview of nativism, suggesting that nativist sentiments draw both in nationalist/patriotic ideas about a given country, and consonantly, a fear of immigrants and Others (often non-white Others). Nativism can this be understood as a preference for people/ideas that are seen as 'native' to one's own country and at the same time, 'a fear/hatred of everything that is non-native' (Immerzeel et al. 2015: 266). Harteveld et al. (2015) suggest that within Europe, nativism is a strong predictor of PRR voting, and as such warrants attention - particularly in relation to women's support for PRR parties. Understanding the relationship nativism and gender, however, is rather complicated; Mudde (2007, 113) argues for example, that there is little variation by gender in relation to expressions of nativism: 'the difference between men and women in terms of nativist attitudes is far from striking, if at all present' while Coenders et al. (2004) argue that in some cases women are more likely than men to express nativist opinions. In their comparative study of PRR parties in Europe, Harteveld et al. (2015) suggest that while men and women express similar levels nativist sentiments, they maintain that women are less likely to vote for PRR parties. Immerzeel et al (2015) on the other hand, suggest that men are more likely to be attracted by nativism than women. This 
chapter seeks to provide further insights into this debate by presenting data from female PRR supporters, specifically UKIP supporters; I argue that nativism is interpolated by our female interviewees in highly gendered ways, and is an important part of our participants' motivations for supporting UKIP. This chapter maintains that for these women, expressions of nativism focus largely on the threat of Islam on British culture and values. In particular the threat of Islam in relation to women's rights is highlighted as a key issue, and interviews suggest that participants see 'indigenous', British women as fully-fledged citizens in a gender equal nation, while Muslim women are seen as subjugated by their culture. This chapter adds to extant research on women's support for PRR parties by demonstrating the importance of this dyadic trope in the narratives of these interviewees.

\section{Methodology}

This chapter draws on data gathered as part of a British Academy/Leverhulme-funded qualitative study of women supporters of nationalist organizations in the UK; specifically UKIP, the English Defence League, and the British National Party. The data informing this chapter are drawn from 11 in-depth semi-structured interviews with UKIP supporters. Having failed to secure access to UKIP members via UKIP themselves, participants were recruited via their participation on UKIP Facebook pages, and specifically by private messaging those who were actively posting, or contributing to existing posts, on such pages. The effect of Facebook privacy settings was such that up to $90 \%$ of all messages were directed to the 'other folder', meaning it is highly likely that the bulk of those approached would have been unaware of our communication unless they happened to check the content of this folder. With only a $10 \%$ response rate, allied to those recipients who refused to participate in the project, the population sample was very small, entirely self-selected, and lacking in any capacity for substantive representativeness, or even purposive sampling. In the main, and in the interests of viability, the interviews were conducted via Skype or telephone. Research suggests that: where participants receive informational support in advance, where interviews take place at a convenient time for the participant, and where care is taken to establish rapport, then telephone/Skype interviews can produce rich data, and may even prove preferable to face to face interviews in facilitating open and frank dialogue (Drabble et al. 2016). Certainly, the lengthy and semi-structured nature of the interviews enables the generation of a rich and nuanced dataset, with some significant degree of saturation. We present data from eleven participants here, all of whom consider themselves to be UKIP supporters. Participants had an older profile, with two aged 40-59, three aged 50-59, and six over 60. Four reported themselves as married, five as single, one widowed and one as dating. Nine described themselves as straight, and two as lesbian. Four participants were educated to graduate level, two to tertiary level, three to secondary level, and two declined to comment. Six were retired, three were selfemployed, and two were employed in semi-skilled or unskilled capacity. All identified their country of birth as English and their ethnicity as white. Three identified themselves as practicing Christians, three as nonpracticing believers, one as agnostic, and four as atheists. Four confirmed themselves as UKIP members, and seven as voters/supporters.

\section{Gender and PRR Parties: The Case of UKIP}

Many have argued that UKIP is best understood as a PRR party (Abedi and Lundberg 2009; Ford and Goodwin 2014; Clarke et al. 2016; Evans and Mellon 2016; Hayton 2016). Lynch and Whitaker (2013) suggest that immigration, concerns about Islam, and euro-skepticism are all key issues of concern for this group of voters, and maintain UKIP voters tend to have lower levels of trust in mainstream parties/politicians. In a similar vein, Ford, Goodwin, and Cutts (2012) argue that while euro-skepticism is a main driver for many UKIP supporters indeed, 99\% of UKIP supporters voted to leave the EU in the 2016 referendum (IPSOS Mori 2016) - other attitudinal drives such as xenophobia and dissatisfaction with mainstream political parties are also important. Their quantitative study of 6000 UKIP supporters suggests that there are two types of UKIP voters - strategic voters and core supporters. Strategic voters, they argue, are more likely to be older, middle-class men who are financially secure, and share similar attitudes with Conservative party voters. While strategic voters express 
relatively high levels of racism and xenophobia, these are much lower than for the core supporters. Core supporters, they argue, share many of demographic features of those who support the far-right British National Party (BNP) - they are likely to be working-class, have familial political histories associated with the Labour Party, and report struggling to live on their current incomes. UKIP supporters are generally older than BNP supporters, however, and while they share a sense of dissatisfaction with the mainstream parties, they are more moderate than those who support the BNP. The fact that UKIP's core support base has similar attitudinal features to far-right supporters is concerning, and their ability to engage women and older populations (who tend not to support the BNP), suggests that UKIP is a polite alternative to the BNP (Ford, Goodwin, and Cuts 2012).

Others have outlined hypotheses that point to feelings of nostalgia and cultural nationalism as explanatory factors (Hayton 2016; Thorleifsson 2016). Thorleifson (2016) in her study of former mining communities in the north of England (Doncaster specifically), suggests that this nostalgia, and the attendant support for UKIP, must be understood within the context of a post-Fordist, hyper-capitalist society that has left many areas like Doncaster in precarious positions. 'Contrary to only framing migrants and minorities as dangerous and polluting others, the Ukip [sic] supporters I interviewed framed newcomers as competitors in a precarious labor market, a factor driving anti-immigrant sentiment' (2016, 563). Thorleifsson suggests that in her study, white as well as non-white residents expressed these anxious sentiments. In a similar vein, Hayton (2016) argues that the politics of national identity are key to understanding UKIP's electoral base, and suggests that UKIP supporters are typically concerned with immigration. He cites research from Lord Ashcroft on UKIP support that maintains these concerns are "emblematic of a deeper "dissatisfaction with the way they see things going in Britain" particularly in cultural terms' (Hayton 2016, 401). UKIP, Hayton argues, taps into pride about Britishness and its members are doubly compelled, both by UKIP's anti-immigration stance, and by its focus on preserving traditional 'Britishness'. Hayton cites the 2015 UKIP manifesto, which pledged specifically to celebrate 'Britishness' by taking pride in 'our country' and to 'promote a unifying British culture' (UKIP Manifesto 2015, in Hayton 2016, 403).

Akkerman $(2015,38)$ argues that 'gender issues have traditionally been important to the ideological profile of populist radical-right parties.' Gender in the PRR, she maintains, has often been characterized by the same conservative ideas about the valorization of the heteronormative family and the enshrining of normative gender roles. However, many studies on PRR parties (Kitschelt 1995; Norris 2005; Mudde 2007; Akkerman 2015) suggest that a shift within some European PRR parties has altered the political terrain. Rather than emphasizing traditional gender roles, many PRR parties have strategically employed ideas related to embrace gender equality and same-sex partnerships as a way to more clearly highlight the problems associated with immigrant Others. Akkerman (2015) suggests the PRR's renewed interest in gender issues is predicated on two key developments: the first is the heightened threat of Islam since 9/11, which resulted in an increased concern about immigration and integration, and focuses on Islam as a particular threat to western democracy. The second is related to the issue of family migration, which has gained political prominence in many European countries, and replaces concerns about work and refugee immigration. As such, she maintains that 'debates about immigration and integration therefore increasingly focus on the family and the status of women' (Akkerman 2015, 40).

While UKIP has long been concerned with issues related to EU membership and relatedly, immigration (Ford and Goodwin 2014; Clarke et al. 2016) they have only recently started to concern themselves with issues related to gender inequality. The 2014 Manifesto, for example largely focuses on wresting national control from the European Union - neither gender nor issues related to women's rights are mentioned at all. The 2015 Manifesto is a more developed document, and goes into more detail about concerns related to Muslim extremism and immigration. Concerns about gender and sex are highlighted in relation to education, including allowing parents to opt their children out of sex-education classes and addressing gender imbalances in the sciences; pushing for the increase of 'father's rights' in relation to custody splits, and one mention of female genital mutilation (FGM) is included in the section on 'British Culture' (UKIP 2015, 61), making clear that FGM is a cultural issue that needs to be addressed in order to unify and 'reinvigorate' British culture. 
By 2017, however, the Manifesto is much more obviously concerned with gender equality. Margot Parker, a UKIP MEP, is included in the Manifesto as the Women and Equalities spokesperson, and there are a number of pledges related to women's rights. Parker is quoted in the Manifesto in relation to the expansion of affordable childcare as saying: 'Affordable, safe childcare is vital if we are to help women obtain or return to work. We simply cannot afford to have highly skilled, highly trained women leaving the workplace, especially not if they are working in public service industries such as nursing and teaching' (UKIP 2015, 27). The specific mention of nursing and teaching, industries that are highly feminized and traditionally associated with women, is an important caveat here in their attention to women's rights. Equally problematic is their discussion of gender equality in the section entitled 'Britain United Under One Law For All', where concerns about gender are very much framed as past of a wider discussion on British culture and values. The first paragraph that speaks volumes about women's rights and clearly frames the political message (and is worth noting in its full form):

If we compare the rights of women in the UK to those of the majority of women overseas, the contrast is striking. Acceptance of the concept of sexual equality is largely confined to a handful of economically advanced nations. Mass uncontrolled immigration has opened the door to a host of people from cultures with little or no respect for women, yet when their views have been challenged, some on the 'Left' of politics, in particular, have encouraged them to claim a 'victim' status they do not deserve. UKIP will challenge those who do not uphold the rights of women, or who set themselves on a deliberate collision course with core British values of equality, free speech and democracy. We will protect all women, regardless of their race, ethnicity or religion. Culture is not an excuse for crime, nor is ignorance of the law (UKIP 2017, 36).

Honour-based violence, polygamy and child marriage, and FGM are highlighted in this section as the most critical issues that demand immediate attention; there is no mention of how UKIP would address issues like the gender wage gap, increasing the number of women in politics, or addressing domestic or sexual violence for other groups of women. The clear progression in a relatively short space of time is important here for understanding UKIP's position as a PRR party, recognizing issues relevant to many women, for example providing childcare to allow to continue working, could be seen as relatively progressive for a PRR party, if not for the specific mention of 'appropriate', feminized roles for women in the labor force (i.e. nurses or teachers). Equally, devoting large sections of the manifesto to women's rights would also be a progressive move forward if these issues were framed almost exclusively as problems of 'culture'. While immigration is clearly an underlying concern for UKIP, so is the maintenance of what they see as 'British' values. Women's rights only become priorities when they are understood as under threat from an 'uncivilized' Other.

\section{Interview Data}

Concerns about Islam and its impact on women's equality was something that clearly emerged from interviews with female UKIP supporters. This was often framed in a way that suggested that 'indigenous' women had already obtained gender equality, and highlighted the threat that Muslim Others posed in taking away these freedoms.

Anna, a retired woman living in the north of England, speaks at length about the ways in which women's role in society has changed, noting both their inclusion in politics, but also highlights other ways in which women have become more emancipated:

Anna: I think women are now more open to politics and because more women are out being breadwinners, as opposed to mothers or just to help the family income. I mean women have careers now, which wasn't heard of when I left school. 
Like many other participants, Anna expressed feelings of fear about being, as she says, 'overrun' with immigrants who refused to integrate and live the 'British' way of life. Carole, a 55-year old woman living in near the Scottish borders, echoes this and notes that she is afraid about losing her identity. The threat of Islam in particular is threatening not just her sense of Englishness, but the country's more widely:

Everybody is losing their identity, every country is losing its identity: It's alright if [immigrants] want to become English and live like the English but there are certain races and religions that do not - in fact they hate the English... if it goes on like this one day there will be no individual countries anymore, it'll all be one big middle-eastern mishmash and it's a shame to lost all this beautiful country and heritage.

The threat of Islam looms large here - the 'beautiful country and heritage' are at risk from immigration, and the specific fear about England becoming a 'middle-eastern mishmash' makes clear that some immigrants are more dangerous than others. While nativism can been seen here in both the expression of patriotism and the fear of the foreign Other, it is clear that Muslim migrants present to most challenging obstacle. Karen, a pensioner living in the midlands, expresses similar concerns, She notes that in her local shopping area there is 'hardly a British shop left', and notes that Polish and Romanian shops have taken over, making her feel like a 'stranger' in her own country. While Karen is concerned about the rise of immigration at a general level, she expressed specific reservations about the threat to Britishness vis-à-vis the threat of Sharia Law

Karen: You know, if you want to live under Sharia Law, live in a Muslim country. I really don't understand why people come here to live in Britain, the British way of life. Well, they don't want to live the British way of life. They come here with the intent to change it and I certainly wouldn't want it changed, not for Sharia Law anyway.

While Karen worries about the lack of British shops and the threat that Eastern European immigrants pose, the threat to Britishness really comes to fore when considering Muslim migrants. Here, nativism is expressed in both the ways that she imagines 'the British way of life' and the fear and anxiety that she displays in relation to the Muslim Other. Karen's support for UKIP is very much predicated on the UKIP will defend English values. She notes:

I'm very proud of British people, our English people, because they do accept everyone as long as they're getting on with it and leaving well enough alone. But the trouble with immigrants, especially Pakistani immigrants...is they're manipulative, they've very devious...they want to change everything so it's their way and they're actually crushing our way of life

The valorization of the British people and the English way of life is held up here rather ironically as being great because it is tolerant and open. The patriotic sentiments expressed here - a central tenant of nativism - must be understood contra the threat posed by the Other trying to destroy this way of life. Karen supports UKIP because they seek to both defend the English values that she holds sacred, and to rid the country of the Others who would attempt to derail this nationalist vision.

Similarly to Karen, most of our participants spoke at length about the threat that Muslim immigrants posed not just in relation to immigration, but also related to the fear that Islam would undermine British values. While these women understood Britishness in a variety of ways, they all agreed that one of the fundamental foundations of Great Britain was its attention to gender equality. Like the discourse laid out in the UKIP manifesto, there was little concern about issues like the gender pay gap, rates of domestic and sexual violence, or women's representation in Parliament. Rather, the focus was squarely on Islam. In the main, our participants suggested that Muslim women were victims of misogyny posed by the Islamic faith. UKIP was seen as a party that would work to dismantle Islam and critically, weren't afraid of being politically incorrect. Most of our interviewees noted 'political correctness' was a key factor that prevented mainstream political parties from standing up for British values, which for our participants, includes the prioritization of gender equality. Paula, a 
retiree living in the northeast of England, expresses concerns about the subjugation of Muslim women, and suggests that both the burka and Muslim women's lack of access to education are particularly problematic:

Paula: It's like subjugation of [Muslim] women, they're subjugated; they're below the man. I don't believe in wearing the burka. I think that's wrong. Some of them don't like them being educated. Well to me, that's akin to apartheid. Don't educate them because if you educate someone, they start thinking and standing up for themselves. And that's wrong. I just don't think that lifestyle's right. To me, it's unfair, it's unfair and it's wrong. But if that's the way they want to live, that's the way they want to live but I don't think we need it in Great Britain. I don't like to see them problems here. It's been and gone in the past in history. We had the crusades and we don't want it anymore, you know.

Paula demonstrates the importance of history here, suggesting that Britain had been fighting against the oppression of Islam since the crusades. The focus on British history and the crusades in particular highlights the importance of Enlightenment values. Paula is not simply worried that Muslim women are not being educated, but that they do not want to be educated. The assumption made here about Other women is that they cannot stand up for themselves, while British women can; that they cannot think for themselves but British women can. Emily, a 59-year-old woman living in the south of England, echoes Paula's comments and pinpoints the burka as a source of oppression for Muslim women.

Emily: Well I don't like women wearing burkas for a start. I find them very intimidating and I think it should be like France where they banned the burka because that doesn't reflect very well on women. I don't care if the person thinks that wearing the burka thinks that that is liberating her from the eyes of men. I find that complete and utter rubbish. I think that, according to... if you want to live in England or the UK or western British country, if you want to wear a burka, then you should go to a country where it's the norm to wear a burka because it's very off-putting for ordinary British women to come across women clothed like that. To us it looks like repression and we don't want to see any of our women in this country looking like they're repressed.

Emily looks to France as providing an alternative political approach to managing the problems that Islam present for women. By banning the burka, France has taken proactive steps to ensure that women are 'liberated' from this symbolically problematic piece of clothing. Her assertion the burka 'looks like oppression' and that there is a national reluctance to see women experiencing repression suggests that 'indigenous' women don't experience repression. This discourse can be seen in the following excerpt from Alison's interview:

Alison: the fundamental Muslims - that was a shock for me. I'd never heard people talk like that about women but generally even the men from Albania and Eastern Europe. They're more chauvinist. Lots of the wives do not work. You know, you say to them 'What does your wife do' 'Oh, she's at home' 'Did she go to university?' 'Yes' 'Doesn't she go to work?' 'No, she's at home with the children'. They are, as you get further and further into Eastern bloc countries, yes I see more traditional views about keeping women down. Yes, they're not emancipated like we are.

Interestingly, for Alison, who lives in the southeast of England, the threat of oppression, while related to Islam in some instances, can also be seen from Eastern European immigrants. Here the discourse that places concerns about gender equality at the heart of 'British values' is also being undermined by chauvinistic ideologies from other groups of migrants. While Islam and its attendant underlying misogyny is overwhelmingly highlighted by the participants as being an impediment to the free flow of seemingly feminist values that are apparently championed in the UK, it was theoretically possible that any Others who came to the UK could undermine these ideals.

All of the participants in our study expressed a great deal of concern about the impacts of immigration on Britishness and British values. While some women spoke about the glorious history of Britain, some about the 
open and tolerant nature of British people, some of the beauty and heritage of England - almost all of them spoke specifically about gender equality as a key feature of the UK. Little attention was paid to inequalities that have persevered for decades, in spite of feminist efforts to address them - rather the focus was squarely focused in Islam as a misogynistic religion, and the threat this apparently sexist culture presented to the already-equal women in England. Nativism here needs to be understood as both the valorization of the UK as a tolerant, equality-minded country by these self-professed patriots, but it is clear that the participants in this study are worried that Islam will undermine these essentially English values. The threat to English culture is very much gendered here - Muslim women, often uneducated and forced to wear burkas are subjugated by Islam, while British women are fully-fledged citizens who possess the same rights and privileges as their British male counterparts. The fact that women make up only 32\% of the Members of Parliament seems somewhat at odds with this glowing assessment of the UK, as does the fact that 1 in 4 women will experience domestic violence in her lifetime, more than $80 \%$ of company board positions are held by men, or that women in the UK still earn $15 \%$ less than men, despite having legislation in place that makes this illegal. As Mudde (2007) has argued, nativism is an imagined idea - there is little basis in reality here to suggest that gender equality is a defining characteristic of Britishness. However, it is clear that for our participants, their support for UKIP is often predicated in this very assumption, and the attendant xenophobia that allows them to make Islam the scapegoat.

\section{Conclusions}

In conclusion, this chapter has presented evidence from female supporters of UKIP to suggest that gendered expressions of nativism are essential to their support for the UK's most influential PRR party. Akkerman (2015) argues that PRR parties in many European contexts have shifted from safeguarding traditional family values and normative gender roles to framing gender as an issue intrinsically related broadly to mass immigration, and to Islam in particular. This gendered narrative about Islam as a threat to women's equality has been put forward by UKIP in their most recent manifesto, and echoes the concerns from our participants who express anxieties about the influx of immigrants, particularly Muslim migrants. UKIP have incorporated such discourses in a relatively short timeframe, moving from a 2014 Manifesto that does not mention gender equality or Islam at all, to a 2016 Manifesto that is replete with references to concerns about the impact of Other cultures on the rights of women, and British women specifically. This movement allows PRR parties to demonstrate their commitment to liberal values and the European Enlightment project (Akkerman 2015), and links directly to concerns expressed by our female participants about the threat of Islam to British values. By framing these concerns about Islam as apprehensiveness about gender equality, this allows for a patriotic vision of the UK as a gender equal country to emerge. Muslim women in particular are held up as being victims of a type of misogyny that 'native' women have completely outgrown. It is clear that for female supporters of UKIP in this study, there is little suggestion that they adhere to the traditional, heteronormative discourses that might have previously defined backing for PRR parties. Rather, there is a shift here to focusing on immigration and Islam as threats to Britishness, and in particular as a potential threat to gender equality. As such, it behooves us to pay attention to both the ways in which parties like UKIP deploy these narratives, and how female supporters of PRR parties take up these discourses if we are to understand the gendered dynamics of PRR support in the UK. 


\section{Bibliography}

Abedi, Amir and Thomas Carl Lundberg, 2009. "Doomed to Failure? UKIP and the Organisational Challenges Facing Right-Wing Populist Anti-Political Establishment Parties”. Parliamentary Affairs, 61(1), 72-87.

Akkerman, Tjitske. 2015. "Gender and the radical right in Western Europe: a comparative analysis of policy agendas". Patterns of Prejudice, 49(1-2), 37-60.

Bacchetta Paola and Margaret Power. eds. 2002. Right-wing women. New York: Routledge.

Blee Kathleen. 1996. “Becoming a Racist”. Gender and Society, 10(6), 680-702.

Blee Kathleen. 2002. Inside Organized Racism: Women in the Hate Movement. Berkeley: University of California Press.

Blee Kathleen and Sandra McGee Deutsch. 2012. "Introduction". In Women of the Right edited by Kathleen Blee and Annette Linden 1-21. Philadelphia: Pennsylvania State University Press

Clarke, Harold, Paul Whiteley, Walter Borges, David Sanders, and Marianne Stewart. 2016. Modelling the dynamics of support for a right-wing populist party: The case of UKIP. Journal of Elections, Public Opinion and Parties 26 (2) (04/02): 135-54, http://dx.doi.org/10.1080/17457289.2016.1146286.

Coenders, Marcel, Merove Gijsberts and Peer Scheepers. 2004. "Resistance to the presence of immigrants and refugees in 22 countries". In Nationalism and Exclusion of Migrants: Cross-National Comparisons edited by Mérove Gijsberts, Louk Hagendoorn and Peer Scheepers 97-120. Aldershot: Ashgate.

Drabble, Laurie, Karen Trocki, Brenda Salcedo, Patricia Walker, and Rachael Korcha. 2016. "Conducting qualitative interviews by telephone: Lessons learned from a study of alcohol use among sexual minority and heterosexual women”. Qualitative Social Work, 15(1), 118-133.

Evans, Geoffrey and Jon Mellon. 2016. "Working Class Votes and Conservative Losses: Solving the UKIP Puzzle" Parliamentary Affairs, 69(2), 464-479.

Ford, Robert, and Matthew Goodwin. 2014. Understanding UKIP: Identity, social change and the left behind. The Political Quarterly 85(3), 277-84.

Ford, Robert., David Cutts and Matthew Goodwin. 2012. "Strategic Eurosceptics and Polite Xenophobes: Support for the United Kingdom Independence Party (UKIP) in the 2009 European Parliament Elections". European Journal of Political Research, 51(2), 204-234.

Harteveld, Eelco, Wouter Van der Brug, Stefan Dahlberg, and Andrej Kokkonen. 2015. "The gender gap in populist radical-right voting: examining the demand side in Western and Eastern Europe". Patterns of Prejudice, 49(1-2), 103-134.

Hayton, Richard. 2016. The UK independence party and the politics of englishness. Political Studies Review 14 (3) (August 01), 400-10.

Immerzeel, Tim, Hilde Coffé and Tanja van der Lippe, T. 2015 "Explaining the Gender Gap in Radical Right Voting: a Cross-National Investigation in Western European Countries". Comparative European Politics, 13(2), 263-86. 
IPSOS-Mori. 2016. "How Britain voted in 2015". [Online]: IPSOS-Mori. Available at: https://www.ipsos.com/ipsos-mori/en-uk/how-britain-voted-2015 Accessed 1 September 2016.

Kitschelt, Herbert. 1995. The Radical Right in Western Europe. Ann Arbor: University of Michigan Press.

Koronaiou, Alexandra. and Alexandros Sakellariou. 2013. "Reflections on 'Golden Dawn', community organizing and nationalist solidarity: helping (only) Greeks”. Community Development Journal, 48(2) 332-338.

Lynch, P. and Whitaker, R. 2013. "Rivalry on the right: The conservatives, the UK independence party (UKIP) and the EU issue.". British Politics 8 (3): 285-312.

Mayer, Nonna. 2013. "From Jean-Marie to Marine Le Pen: Electoral Change on the Far Right". Parliamentary Affairs 66, 160-178.

Moffitt, Benjamin, and Simon Tormey. 2014. Rethinking populism: Politics, mediatisation and political style. Political Studies 62 (2) (06/01; 2017/10): 381-97, https://doi.org/10.1111/1467-9248.12032.

Mudde, Cas. 2014. Fighting the system? populist radical right parties and party system change. Party Politics 20 (2) $(03 / 01 ; 2017 / 10): 217-26$, https://doi.org/10.1177/1354068813519968.

Mudde Cas. 2009. "Populist Radical Right Parties in Europe Redux”. Political Studies Review, 7(3), 330-7.

Mudde, Cas. 2007 “Populist radical right parties in Europe”. Cambridge: Cambridge University Press.

Mudde Cas. 2004. "The Populist Zeitgeist". Government \& Opposition, 39(3), 541-563.

Norris, Pippa. 2005. Radical right: Voters and parties in the electoral market. Cambridge: Cambridge University Press.

Spierings, Niels, Andrej Zaslove, Liza M. Mügge, and Sarah L. de Lange. 2015. Gender and populist radicalright politics: An introduction. Patterns of Prejudice $49 \quad(1-2)$ (03/15): 3-15, http://dx.doi.org/10.1080/0031322X.2015.1023642.

Spierings, N. and Zaslove, A. (2015) Gendering the vote for populist radical-right parties. Patterns of Prejudice Vol 49(1-2) 135-162.

Thorleifsson, Cathrine. 2016. From coal to ukip: The struggle over identity in post-industrial doncaster. History and Anthropology 27 (5) (10/19): 555-68, http://dx.doi.org/10.1080/02757206.2016.1219354.

UKIP. 2014. UKIP Manifesto: Creating and Earthquake. [Online]: UK Independence Party. Available at: https://d3n8a8pro7vhmx.cloudfront.net/themes/5308a93901925b5b09000002/attachments/original/1398869254 /EuroManifestoLaunch.pdf?1398869254

UKIP. 2015 UKIP Manifesto: Believe in Britain. [Online]: UK Independence Party. Available at: https://d3n8a8pro7vhmx.cloudfront.net/ukipdev/pages/1103/attachments/original/1429295050/UKIPManifesto2 015.pdf?1429295050

UKIP. 2017. UKIP Manifesto: Britain Together. [Online] UK Independence Party. Available at: https://d3n8a8pro7vhmx.cloudfront.net/ukipdev/pages/3944/attachments/original/1495695469/UKIP_Manifesto June2017opt.pdf?1495695469 
Van Der Brug, Wouter and Joost Van Spanje. 2009. "Immigration, Europe and the 'new' cultural dimension". European Journal of Political Research, 48, 309-334.

Webb, Paul, and Tim Bale. 2014. "Why do Tories defect to UKIP? Conservative party members and the temptations of the populist radical right". Political Studies, 62(4), (December 01), 961-70.

Weyland, Kurt. 2001. "Clarifying a contested concept: Populism in the study of Latin American politics". Comparative Politics, 34(1), 1-22. 